\title{
LOS ORÍGENES DEL INSTITUTO PROVINCIAL DE HIGIENE DE LAS CANARIAS ORIENTALES Y LA SANIDAD MUNICIPAL (1926-1927): CAMBIOS ESTRUCTURALES Y ASISTENCIALES
}

\author{
Juan Francisco Martín del Castillo
}

I.E.S. Mesa y López (Las Palmas de Gran Canaria)

\begin{abstract}
RESUMEN
El Instituto Provincial de Higiene de las Canarias Orientales es un ejemplo de la puesta en marcha del Estatuto Provincial de José Calvo Sotelo (1925). Envuelto en medidas administrativas y repartos financieros entre el Ayuntamiento de Las Palmas de Gran Canaria y el Cabildo Insular, su inicio es obra directa del doctor Antonio Ortiz de Landázuri, en aquellos momentos al cargo de la Inspección de Sanidad. En el presente, quedan descritos la estructura y funciones del Instituto de Higiene, además del pase de los miembros facultativos de los laboratorios y estaciones de anteriores servicios municipales del ramo.
\end{abstract}

PALABRAS CLAVE: Sanidad, Higiene Pública, Instituto Provincial, Islas Canarias (Provincia Oriental), Siglo XX.

\section{SUMMARY}

The «Instituto Provincial de Higiene de las Canarias Orientales» is an example of Estatuto Provincial of José Calvo Sotelo (1925). Involved in administrative affaires and economical distributions between the Townhall of Las Palmas de Gran Canaria and Insular Council, its beginning is labour of Doctor Antonio Ortiz de Landázuri, in that moment Health Inspector. In this paper, be described the structure and functions of Hygiene Institute, so the change of technical members of laboratories and stations of previous town health services.

KEY WORDS: Public Health, Hygiene Institute, Canary Islands (Oriental Province), XX Century.

\section{INTRODUCCIÓN}

En el marco de la Salud Pública de la administración periférica destacan, sobremanera, los cambios introducidos por las nuevas reglamentaciones del 
área ${ }^{1}$. Desde principios del siglo XX, en España se han experimentado diversas proyecciones que han dado lugar, como es obvio, a diferentes modelos sociosanitarios y asistenciales. En la que nos cita, la experiencia de las Brigadas Sanitarias Insulares, que ya de por sí supuso un trastoque administrativo para las corporaciones locales, al perder buena parte de sus competencias e, incluso, personal cualificado, dio paso al Instituto Provincial de Higiene de las Canarias Orientales. Curiosa denominación, en primer lugar, porque aún no existía tal provincia oriental, decretada en $1927^{2}$. Además, apenas había entrado en funcionamiento las anteriores Brigadas Sanitarias, cuando ya se disponía un cambio ulterior. En cierta forma, la administración insular no daba abasto con las disposiciones legales, pese a que, en realidad, los ajustes resultantes sólo harían mudar las cosas en apariencia.

Los Institutos Provinciales de Higiene fueron creados por el Estatuto Provincial de 1925 (denominado de "Calvo Sotelo») ${ }^{3}$, cuya novedad principal era la implicación solidaria de los diferentes estamentos locales y regionales en el desarrollo de las tareas de la salud pública y las de beneficencia. No obstante, sus atribuciones también compartían fines preventivos y analíticos. Sobre el último aspecto, resulta que funciones como la bromatológica, antaño perteneciente a la esfera consistorial, ahora pasará a ser desempeñada por personal afecto al nuevo Instituto. En Canarias, tal fenómeno es particularmente interesante, por cuanto el Laboratorio Municipal de Higiene ${ }^{4}$, con sus dos secciones, quedará inscrito en el incipiente. Podrá suponerse el desconcierto que la situación atrajo sobre sus facultativos y personal auxiliar, amén de la redefinición administrativa de los puestos individuales y las competencias técnico-científicas en que ello derivaría. Sin embargo, las bases del proyecto del Instituto Provincial venían a apaciguar esos ánimos y, en cierto sentido, a refrendar el trabajo realizado. No sólo deja a cada cual lo suyo, incluso en lo pecuniario, sino que muestra un exquisito respeto por la labor ya ultimada. Con respecto al personal sin cualificación, también se le mantiene en igual condición y categoría.

1 Sobre el período y los Institutos Provinciales de Higiene, véase: PERdiguero, E.; BernABEU, J.; RoBles, E. (1994), «La Salud Pública en el marco de la administración periférica: El Instituto Provincial de Higiene de Alicante (1924-1936)». Dynamis, 14, 43-76; MEdINA, R. M. y RODRÍGUEZ, E. (1994) «Profesionalización médica y campañas sanitarias. Un proceso convergente en la medicina española del primer tercio del siglo XX». Dynamis, 14, 77-94.

2 Por medio del Real Decreto Ley de 21 de septiembre de 1927. Cfr. GuIMERÁ, M. (1987) El Pleito Insular (1808-1936). Madrid, Instituto de la Administración Local, 2a . ed.

3 Sobre su impacto en Canarias, véase: GUIMERÁ (1987), pp. 436-439.

4 Cfr. Martín del Castillo, J. F. (1996) Los primeros laboratorios de Las Palmas (1904-1926). (Una aproximación). Las Palmas de Gran Canaria, Ayuntamiento. 
La esperanza del cambio, con todo, partía de la apuesta conjunta de medios y recursos humanos. Sabido es que, como práctica habitual, las administraciones iban cada una por su lado, pese a responder a un criterio jerárquico. En lo sanitario, ello producía singulares desencuentros entre instituciones ${ }^{5}$, a veces solventados por Madrid. Por ende, la naturaleza de un Instituto Provincial habría de menguar tales roces con una mayor participación de las corporaciones, repartiéndose el gasto y las funciones administrativas. El resultado esperado, en conclusión, sería una atención más solícita y esmerada, no menos que rápida y eficaz.

En 1925, pues, comienza la verdadera aventura normativa, que luego habría de continuar en la República. Durante la Dictadura de Primo de Rivera, al decir de los especialistas 6 , se produce una mayor intensidad en la activación de las políticas relacionadas con la esfera sanitaria. El Reglamento de Sanidad Provincial, de 20 de octubre de 1925, disponía la fusión de las anteriores instancias higiénico-sanitarias, incluidos los laboratorios que habían ido creándose en los primeros años de la centuria. En lo que respecta a la urbe grancanaria, aunque atañe por igual a las islas orientales, la gestación del mismo Instituto obligaba a un esfuerzo de entendimiento, y encuentro de criterio único, al Laboratorio $\mathrm{Mu}$ nicipal de Higiene con varias secciones, a la Jefatura Municipal del mismo ramo, a las Brigadas Sanitarias, que tantos miedos despertaron, sobre todo entre los facultativos, que las llegaron a denominar «cacicato» administrativo por su tendencia al centralismo ${ }^{7}$, y a los distintos profesionales de la medicina que, de alguna manera, veían sus pasos dirigidos por la neonata instancia.

Los cometidos y funciones del Instituto Provincial de Higiene de las Canarias Orientales, comandado por el doctor Antonio Ortiz de Landázuri ${ }^{8}$, con

5 Como, por ejemplo, con los responsables sanitarios del puerto. Cfr. MARTín DEL CASTILlO, J. F. (1997) «Primeros pasos de la Estación Sanitaria del Puerto de Las Palmas y la prevención marítima (1901-1913)». Revista de Historia Canaria, 179, 161-179.

6 Huertas, R. (2000) «Política sanitaria: de la Dictadura de Primo de Rivera a la II República». Rev. Esp. Salud Pública, 74, 35-43.

7 (A)rchivo (H)istórico (P)rovincial de (L)as (P)almas, Ayuntamiento, Actas Municipales (Microfilm, rollo $\mathrm{n}^{\circ} .39$ ), sesión del 23 de marzo de 1923, fol. 51v.

8 Por desgracia, no existe en los archivos consultados, ni en el Provincial de Las Palmas ni en los periódicos de la época (Hemeroteca del Museo Canario), información explícita sobre el individuo. Esto es, la relativa al origen familiar y a la formación académica. Tampoco están registradas publicaciones a su nombre, o al del Instituto Provincial de Higiene, en la bien surtida biblioteca del citado Museo grancanario. De otra parte, parece estar emparentado con la renombrada saga de médicos de iguales apellidos, aunque sólo disponemos de la certeza de su doctorado por la Universidad Central (Facultad de Medicina) en 1923 (Contribución al 
rango de inspector sanitario, eran amplísimos, quizás tan amplios que hacían sospechar, desde un inicio, de la posibilidad de llevarlos a término. Tenía competencias en el régimen interior, esto es, en el control y asistencia de la enfermedad sobrevenida en el propio territorio, el cuidado bromatológico de los alimentos, el análisis científico de las aguas de abasto y de albañales, el nivel sociohigiénico de los núcleos de poblaciones - antes labor directa de las Jefaturas Municipales-, y, por si fuera poco, debía coordinar su personal y actividades con el régimen exterior, aún en manos del Director de Sanidad Exterior, que, en las islas, revierte a la instalaciones portuarias, donde solían (y suelen) asentar sus dominios 9 .

Realmente, la historia sanitaria del archipiélago canario dibuja una conocida y estudiada trayectoria, cíclica en muchos aspectos. Agobiado por el ataque infeccioso de procesos contagiosos de índole internacional, por lo común llegados por vía marítima, ha salido mal que bien del paso merced al entusiasmo y entrega de unos cuantos voluntarios de la medicina insular, que, eso sí, mostraban una preparación muy digna labrada en Francia o Inglaterra. Este mismo voluntarismo profesional es el que asiste a la población residente $\mathrm{y}$, en especial, a los déficits provocados por las carencias de los desfavorecidos y las casi nulas condiciones de salubridad de los sectores marginales, enclavados en los aledaños de los barrios porteños, como el de La Luz. Obvio resulta decir que, cuando semejante equilibrio higiénico y sanitario - por llamarlo de alguna manera-, se veía perturbado con una epidemia descontrolada, la penuria campaba a sus anchas, al menos por cortos períodos de tiempo, hasta el completo restablecimiento del ínfimo estándar asistencial. Muchas veces tal estado de cosas, harto frecuente en la administración sanitaria periférica e insular, llevó a los médicos comprometidos a presentar denuncias en los medios locales, prestando su voz a aquellos que no la tenían. Es más, algunos dejaron de lado los discursos, descubriéndose en la ejecución de proyectos higiénicos de altura, que hoy suponen un elogioso recuerdo para la historia de la medicina canaria. Iniciativas como el Instituto de Vacunación de las Palmas (18941895) formarían parte de ese buen hacer médico y social ${ }^{10}$.

Pero, el Instituto Provincial había de cubrir iniciativas no sólo públicas sino privadas. Quiere decirse que, tras su implantación y en óptimas funciones,

estudio del germen de la pseudotuberculosis de los roedores y sus principales diferencias con el cocobacilo de Yersin, 30 hojas, inédita).

9 MARTín DEL CASTILlo (1997).

10 Martín Del Castillo, J. F. (1996) «La Escuela Serológica Francesa y la creación del 'Instituto de Vacunación' en Las Palmas de Gran Canaria (1894-1895)». El Museo Canario, LI, 193-210. 
la recurrencia a galenos de pago para las tareas más cotidianas ya no sería tan extendida entre la población, confundiéndose con una supuesta obligación social, sino una opción más. Cualquier individuo, fuera quien fuese, recibiría una atención integral en el Instituto. En una entrevista, reproducida en el Diario de Las Palmas, de principios de 192711, el reluciente Director e Inspector, Ortiz de Landázuri, hace gala de una honda preocupación sociomédica y persevera en el empeño de asistir a los que menos poseen de la sociedad. Loable donde los haya, por supuesto, mas lo relevante no es la entidad del compromiso sino el hecho de realizarlo en voz alta. No era una reflexión para sus interiores sino un diseño asistencial a cumplir.

En tiempos pasados, aunque no tanto porque se mantenía tal hábito en el cambio de siglo, la medicina preventiva y social pertenecía de suyo a la beneficencia municipal o a la caridad de los más ${ }^{12}$. Se ha demostrado que, en el colmo de la dejadez administrativa en el ramo sanitario, no había constancia de un padrón de la indigencia en la ciudad grancanaria ${ }^{13}$, no obstante perseguirse en años posteriores. La pobreza de solemnidad quedaba ubicada en la leja de los imprevistos del municipio. Por no contar o por no saber, los dineros gastados en la vacunación de este tramo poblacional eran desconocidos y la Inspección Municipal de Sanidad se veía en mal trance al explicar las cuentas de la previsión vacunatoria. Otrosí puede pronunciarse de los enfermos crónicos, sin posibles para su manutención, que desangraban, apenas sin saberlo, a la administración del Consistorio y que, en última instancia, dependían del cuidado de los voluntarios de la Cruz Roja Española.

En suma, el Instituto Provincial de Higiene daría remedio a lo descrito y organizaría la función sanitaria. Ese era el plan estratégico de la normativa y, sobra decirlo, de Ortiz de Landázuri.

\section{ANTECEDENTES DEL INSTITUTO PROVINCIAL DE HIGIENE.}

En este apartado, de intenso recorrido, se ha de intentar describir y explicar los desarrollos higiénico-sanitarios que desembocaron en la creación del Instituto de las Canarias Orientales. Sirvan dos precisiones de necesario exor-

11 Diario de Las Palmas ( $\mathrm{n}^{\circ}$. 13.143), «El Instituto de Higiene de Canarias Orientales: III y último», sábado, 5.III.1927.

12 Martín Del CASTILlo, J. F. (1996), «La Cruz Roja Española y la beneficencia municipal en Las Palmas de Gran Canaria (1912-1919)», Anuario de Estudios Atlánticos, 42, 911-940.

13 Ibid. 
dio: primera, los ayuntamientos eran dueños de la sanidad urbana por cuanto las Bases generales para la redacción de Reglamentos de Higiene, según la Real Orden de 12 de octubre de 1910, así se lo permitían; y, segunda, derivada de la anterior, cada urbe procede de un modo adecuado a los males que afectan a sus habitantes. Es decir, la previsión falla en gran cantidad de ocasiones, amén de que los índices de morbilidad no son los mismos en una geografía meseteña que en una población insular. En el caso grancanario, el norte de la política sanitaria fue mantener limpio el Puerto de La Luz, foco de atracción económica y polo de desarrollo de la isla al completo. Los sacrificios, conflictos, desvíos e intereses varios priman esta realidad, sobre la que pivotan circunstancias que conectan directamente con lo médico y sanitario.

\subsection{Las Brigadas Sanitarias Insulares.}

En 1923, años antes de la creación del Instituto Provincial de Higiene, llegaba a los plenos del Ayuntamiento de Las Palmas de Gran Canaria el adelanto de las medidas sanitarias, consecuencia remota de la Instrucción General de Sanidad de 12 de enero de 1904. Las discusiones en torno a este asunto derivaron por derroteros políticos y laborales. En especial, aquellos con responsabilidades profesionales en la cuestión, fueran médicos o farmacéuticos, arguyeron diferentes exposiciones que no laudaban, precisamente, las Brigadas Sanitarias. El tono de los argumentos fue unánime en estos individuos, pese a los esfuerzos de la Alcaldía por rebajar el perfil del desencuentro. Según su parecer, las Brigadas no eran sino un ardid de la administración central para recuperar competencias en el ramo y vaciar, en contrasentido, los servicios municipales afectados ${ }^{14}$. Fueron duras palabras de advertencia y gestos inequívocos de la insolidaridad que habría de producirse con la ciudad y la isla si así se obraba desde Madrid.

La excusa para motivar el encendido intercambio de pareceres fue la propuesta, o, por mejor decir, la tajante iniciativa de la Delegación de Gobierno para construir un muro en el interior del Puerto de La Luz, que separara los barcos y a sus navegantes del contacto con la ciudadanía, y declarara la suciedad portuaria a renglón seguido. Un mínimo brote de peste bubónica, en absoluto invasivo $^{15}$, forzó semejante batería de medidas. Como era natural, la respuesta

14 Palabras del farmacéutico Mascareñas, pronunciadas en las sesión del Consistorio de fecha del 23 de marzo de 1923, cit., fol. 52r.

15 Cfr. Martín del Castillo, J. F. (2003), «Sanidad, secretismo y pleito insular: el brote de peste bubónica en Las Palmas de Gran Canaria». Anuario de Estudios Atlánticos, 49, pp. 537-578. 
fue inmediata por parte de los ediles, reprobando la estrategia por desafortunada y exagerada en grado sumo. La diatriba abrazaba por igual a los representantes de la Sanidad Exterior, en aquel momento, y a la Jefatura Insular de Sanidad - que se vio tildada de inoperante y sumisa - ostentada por el veterano doctor Vicente Ruano y Urquía (1852-1924) ${ }^{16}$. Incluso los médicos presentes en las reuniones del plenario, como concejales del Consistorio, desaprobaban las maneras del responsable del área, meramente aquiescente a los dictados de Madrid. Poco habría de sospechar que su suerte política estaba echada a resultas del conflicto ${ }^{17}$.

Las Brigadas, pues, entraron en la madeja de asuntos relacionados con la sanidad. Ya que se veía, en su futura puesta en práctica, un ejemplo más de arbitrariedad y desconsideración hacia las características propias del administrado isleño. El momento más incendiario se produjo, cuando de consuno, el boticario Mascareñas, muy reputado entre la población, y el galeno Valle mostraron su abierta negativa al diseño de las Brigadas. Su visión del particular pretendía encontrar en las estructuras del nuevo modelo el sello del centralismo más desaforado. Ambos asaetearon a la Presidencia del Concejo para que redoblara los esfuerzos en la dirección de someter a crítica los pormenores del servicio y aplicara un duro correctivo, en nombre de la Corporación, a los representantes de la administración sanitaria del Gobierno en la isla.

Realmente, el peligro que entreveían era la incertidumbre de los profesionales y la gobernación de la trama sanitaria a desarrollar. Por mucho que el Alcalde hiciera ruegos conducentes a la calma y el sosiego, previa consulta con las autoridades gubernamentales, el ambiente no cedía en tensión. Se llegó a calificar a las Brigadas Sanitarias, quizás un tanto alegremente, como una moderna forma de cacicazgo centralista. Sin embargo, la controversia no se dilató en el tiempo, puesto que los cambios en la esfera higiénico-sanitaria se arrebataban unos a otros el protagonismo dada la celeridad de su implantación o término. Conocedora de esta situación, por padecerla desde tiempo atrás, los munícipes arbitraron medidas para, de una manera u otra, dejar las cosas en su sitio, el status quo de la sanidad insular y municipal desde los inicios del siglo XX. Ejemplo de ello es la continuidad en el servicio, con idéntico sueldo y categoría, de la mayoría de los empleados, tanto personal médico como subalterno, de la anterior estructura atencional.

16 Sobre su figura, véase el bosquejo de Bosch Millares, J. (1967), La Medicina en Gran Canaria. Gran Canaria, Cabildo Insular, II, pp. 232-235.

17 Ya que le forzó a la dimisión. Véase: La Provincia, «Junta Insular de Sanidad», 7.IV.1923. 


\subsection{El nuevo estatuto sanitario.}

Es a partir de 1925, y sobre todo del siguiente, cuando las administraciones locales caen en la cuenta de un enfoque distinto de la sanidad y la asistencia social. En medida paulatina, se van discutiendo y centrando las necesidades de los servicios médicos y, en paralelo, se aproxima la organización de los Institutos de Higiene dotándoles de una reglamentación acorde con sus funciones y capacidades. Estas últimas distaban de ser mínimas y obedecían a un criterio de atención globalizado en un centro concreto. O, por lo menos, así se entendió en Las Palmas de Gran Canaria. Las primeras plumas que concienciaron en este sentido son las de los periodistas de los medios más leídos, como el Diario de Las Palmas y La Provincia ${ }^{18}$. En más de una oportunidad, los discursos y editoriales de ambas cabeceras actúan como voz del pensar mayoritario de los políticos isleños y, por esa razón, apreciamos su concurso como una fuente documental más en la historia de la medicina canaria a falta de otros aportes de auténtico calado.

El debate municipal del 26 de julio de 1926 fue precedido semanas antes por una campaña de presentación de las posibilidades del denominado «Instituto de Higiene». En los sueltos del Diario, más preocupado por el problema, queda patente la voluntad de allegar la nueva realidad, mostrando las modificaciones con el antaño verificadas, amén de tomar nota de las bondades a introducir. Sobresale en ilustración el artículo, titulado «El Instituto de Higiene y los beneficios del nuevo régimen sanitario», del sábado, 24 de julio ${ }^{19}$, harto explícito en detalles importantes para la ciudadanía. Tuvo enorme acierto el editor al pormenorizar la funcionalidad del servicio, además nomina al responsable del área y, lo mejor, sitúa geográficamente al establecimiento:

«El Inspector de Sanidad de Canarias Orientales, Dr. Ortiz de Landázuri, está realizando una labor silenciosa y fructífera, digna de encomio porque redundará en beneficio público. Contando con los recursos que le facilita el Cabildo Insular, el doctor Ortiz de Landázuri se ocupa activamente en organizar los servicios del Instituto de Higiene creado en Las Palmas.

18 De sobra es conocido que ambos periódicos, por su despliegue y tirada en aquellos tiempos, se han convertido en fuente para el conocimiento del pasado isleño. Además la cobertura informativa, ofrecida sobre el origen y funciones del Instituto Provincial de Higiene, es desde luego inmejorable para disponer de unos mínimos elementos de juicio y análisis históricos. Por último, las dos cabeceras estaban muy cerca de los círculos del poder local, cuando no eran en la práctica sus órganos de expresión.

19 Diario de Las Palmas (nº. 12.960). 
Ya el Ayuntamiento aprobó los planos para la ampliación y reforma del edificio propiedad del Cabildo Insular, situado en la calle Canalejas. Los nuevos pabellones en construcción se destinan al Instituto de Higiene que quedará instalado con la necesaria capacidad.

Contará el inmueble de dos plantas. En la baja se instalarán los servicios siguientes: Dispensario antituberculoso, sala de pasteurización, extracción de vacunas, observación de rabia, consulta de gota de leche y reparto de idem, vacunación, sala de enfermeras, establo de terneros, garage, cocina, horno, salas de espera, almacenes, etc.

En el piso principal se instalarán los departamentos de bacteriología, química, balanzas, vacuna, rabia, autopsias, peste, animales inoculados, disección y administración.

(...) Entra asimismo en las funciones del los Cabildos sostener un instituto de Higiene con los siguientes cometidos: Preparación de los sueros y vacunas preventivos y curativos que necesiten los pueblos de la provincia; diagnóstico de Laboratorio en las enfermedades infecciosas y en el cáncer; transporte de los enfermos infecciosos y urgentes, desde los pueblos hasta el hospital; servicios de desinfección y desinsectación; investigación de las zonas palúdicas; cursos de ampliación de conocimientos sanitarios para los Inspectores municipales de Sanidad de la provincia y divulgación de conocimientos higiénicos».

Fácil se ve la ambición de miras del Instituto de Higiene, o, a lo menos, el gran trazo que para el Diario de Las Palmas habría de tener el servicio interinsular. Importa destacar, no obstante, entre tanta función y diseño, los problemas sanitarios más acuciantes desde el punto de vista estrictamente médico y asistencial. Porque, en el fondo, el artículo no es únicamente una defensa del Instituto sino una declaración en toda regla de la problemática canaria. La tuberculosis, la necesidad de la vacunación reglada y generalizada, los análisis básicos para el correcto diagnóstico de las enfermedades y su posterior detención preventiva son los elementos que componen el índice de asuntos a resolver. El primero, los procesos tuberculosos en sus variadas manifestaciones, ya había sido largamente objeto de reclamo profesional y estudio sintético en el órgano del colegiado más interesante de la época, esto es, la revista La Medicina Canaria, editada en la isla de Tenerife, y que dedicó amplios artículos a dar cabida a las modernas soluciones a la infección ${ }^{20}$. Por ello no

20 La Medicina Canaria. Revista técnica y de intereses profesionales, cuyo director, propietario y fundador era el Doctor Ricardo Castelo, bacteriólogo y Director de Sanidad Exterior en la isla tinerfeña. Los números 34 y 39, de 1926, y el 49 de 1927 incluyen participaciones sobre la tuberculosis. De entre ellos, el más sobresaliente por amplitud es el de Juan Rodríguez López («La tuberculosis en Canarias. Necesidad de adoptar medidas de previsión y defensa», $n^{\circ} .34$, pp. 1-7). 
causa extrañeza el lugar ocupado en el orden de preocupaciones. En cuanto a la extensión de la vacuna, había sido un acariciado deseo, desde finales del siglo anterior, por parte de los médicos grancanarios. Muchos males, de existir un centro de producción de las antitoxinas, jamás hubieran llegado a declararse en las Canarias. Sin embargo, la realidad era muy otra, estando al albur de los estallidos infectocontagiosos sobrevenidos por la recalada de un buque repleto de infestados. Unido a este prurito socioprofesional, de hallar oportunidad propicia a la vacuna en el pueblo, está, cómo no, el acicate de un ajustado diagnóstico, veraz y libre de sospecha. En suma, una línea de laboratorios en acuerdo sistemático con la labor de los profesionales en la vanguardia de la atención médica. Lo regular y habitual era recurrir a los establecimientos de la península, por ejemplo, al Instituto de Alfonso XIII, pero los resultados se demoraban y la urgencia de la situación se ventilaba con la experiencia y voluntariedad de los galenos locales.

En lo que respecta al capítulo sociasistencial también apunta muy alto el Instituto de Higiene. Las labores de atención, e incluso traslado, de los enfermos graves o urgentes parecen estar garantizadas. De otra parte, recoge anteriores iniciativas, de índole benéfica o higiénica, que, de triunfar la institución, harían de su prometido concurso algo imprescindible. Como remate, se insinúa que el Instituto acogería medidas para actualizar los conocimientos de los sanitarios, desde luego un sorprendente desafío para los profesionales de la medicina y la enfermería.

\subsection{El Ayuntamiento y el nuevo régimen sanitario.}

El calado de lo enumerado en el artículo del Diario no deja impávido a cualquiera y, por supuesto, mucho menos a la administración local. El asunto del Instituto de Higiene, así como el alcance final de la propuesta y los ulteriores cambios, fue objeto de debate en el pleno municipal, dos días después de la glosa funcional en el periódico. Así, pues, el lunes, 26 de julio, se da lectura al «proyecto de organización del Instituto Provincial de Higiene de Canarias Orientales ${ }^{21}{ }^{21}$. Ya habían informado las comisiones inmersas, de alguna $\mathrm{u}$ otra manera, en la puesta en práctica de la realización institucional: la de Beneficencia y la de Hacienda y Régimen Interior, sin presentar objeción irreparable al diseño del Doctor Ortiz de Landázuri. No obstante, otro

21 AHPLP, Ayuntamiento, Actas Municipales (Microfilm, rollo nº. 39), sesión del 26 de julio de 1926, fol. 123v. 
punto más difícil eran las bases de la colaboración entre Ayuntamiento y Cabildo Insular, todavía por concretar, para ayudar a financiar y sostener al Instituto. En primera instancia, dos destacados miembros de la Comisión de Beneficencia, Sanidad y Cementerios, don Rafael Ramírez Suárez y don Luis Mena Burgos, estaban por la labor y no escondían su apoyo hacia a la ejecución inmediata del proyecto, lo que lógicamente decantó el panorama hacia la adopción de una acuerdo unánime, fundamentado en seis puntos de importante motivación histórica, ya que sus contenidos describen la red sanitaria y asistencial dispuesta por el Ayuntamiento, aparte de otros detalles de no menor significación. Por ejemplo, en las cláusulas A-D se especifican diáfanamente los traspasos, cesiones y pases del personal de anteriores complejos o institutos al neonato, entre ellos el Laboratorio Municipal al completo y la Brigada de Desinfección; además se certifica la defunción de las Brigadas Sanitarias «al cesar dicho organismo de sus funciones»"22. Pero, también queda uno enterado de la nómina de cualificados técnicos que prorrogan su excelente actividad en el recién creado: Alberto García Ibáñez, Jefe de la Sección Bacteriológica; Antonio Vila Enríquez, Jefe de la Sección de análisis químicos y, cómo no, los respectivos auxiliares que «dependerán en lo sucesivo del Cabildo Insular» ${ }^{23}$. No obstante, el lenguaje modifica el tono cuando se alude al personal subalterno, ya que se dice literalmente que «será preferido para los puestos ó destinos análogos del Instituto» ${ }^{24}$.

La cláusula $\mathrm{E}$, de idéntico primer punto, resulta de lo más relevante porque detalla la contribución económica del Ayuntamiento al sostenimiento del Instituto. En concreto, una cuantía anual de 64.000 pesetas «que se librarán por dozavas partes». Esto es, 5.333,33 pesetas por mes y, con ello, según recoge el mismo texto, quedaría exonerada la ciudad de las obligaciones del artículo 130 del Instituto Provincial. A poco que se razone el presupuesto, y esta última referencia, se hará entendimiento de lo factible de la financiación propuesta, que dista de convertirse en un duro peso para las arcas municipales, y, en otra latitud, hallaremos que el Reglamento del Instituto de Higiene en poco había de ser redactado, aunque desconozcamos el tenor exacto de sus contenidos, habida cuenta que no se ha conservado ejemplar de él que sepamos. A buen seguro, partiría de experiencias peninsulares contrastadas, si bien enmarcadas en la situación isleña.

22 Ibid., fol. 124r.

23 Ibid.

24 Ibid. 
Los representantes del Consistorio en el gobierno del Instituto tampoco quedan en el olvido. O bien la figura del Alcalde asumiría tales funciones o bien un concejal aceptaría desempeñar el cargo. La cláusula $\mathrm{G}$ admite, en un todo, el traspaso del régimen sanitario: «El Instituto vendrá obligado a prestar todos los servicios de su cometido en relación con el municipio de Las Palmas, de suerte que no sean al mismo exigibles como obligación mínima» ${ }^{25}$. El artículo 2, menos programático, discurre por los senderos de la ruda práctica cotidiana, al concretar el trasvase material ${ }^{26}$ :

«El material y enseres que el Ayuntamiento viene utilizando en sus laboratorios y Brigadas de Desinfección que son de su pleno dominio, serán entregados bajo inventario al Excmo. Cabildo Insular...»

El resto del texto acordatorio hace precisiones sobre la posibilidad, en tanto no se concretara el ansiado Instituto, de reinstaurar totalmente el servicio sanitario municipal si aquél no llegara a abrir sus puertas o quedara liquidado antes de empezar. Sobresale, de esta retahíla preventiva, la designación de Rafael Ramírez Suárez ${ }^{27}$, como miembro corporativo en el seno de la futura Comisión de Régimen Administrativo del Instituto de Higiene Provincial. Nada extraño si nos atenemos a la trayectoria personal y política del individuo, señalado por su responsabilidad en el área de la Comisión de Beneficencia, Sanidad y Cementerios ${ }^{28}$. En cierta forma, el Ayuntamiento, avezado en pasadas aventuras legislativas, dentro del mismo sector, muestra una cautelosa conducta y, si nos apuran, una política seguidista con respecto a anteriores diseños sanitarios, pese a la novedad institucional.

A la postre, el nuevo régimen sanitario se impone en lo normativo y administrativo. De ahí la expectación, bien calibrada, de los ediles y representantes de la sanidad municipal. Pero, y esto es indubitable, la realidad presiona para que haya, en efecto, un trasvase de funciones de una institución a otra. Así lo certifica el mismo acuerdo que consigna la dejación de los deberes propios de la asistencia médica en manos del Instituto Provincial. Al parecer, sin grandes contratiempos ni sobresaltos.

25 Ibid., fol. 124r.

26 Ibid., ff. 124r-v, cláusula B del punto 2.

27 Ibid., fol. $124 \mathrm{v}$, punto 4.

28 No en vano era su Presidente por designación oficial, tomada en sesión consistorial del 27 de octubre de 1925 , fol. 80 y ss. 


\section{EL INSTITUTO Y LA SOCIEDAD CIVIL: EL MODELO SANITARIO RESULTANTE.}

Una vez hubo llegado el acuerdo institucional, la promesa de un régimen sanitario nuevo pasaba por hacer partícipe a la sociedad isleña de los parabienes del Instituto de Higiene, presentando a los cuatro vientos todos los pormenores y entresijos que fueran necesarios para que la ciudadanía hiciera suyo el empeño administrativo. En una palabra, había que darlo a conocer, mostrar la estructura, las personas - sobre todo, el director - y las finalidades. Obvia decir que, semejante campaña informativa e institucional, ha hecho mucho a favor del conocimiento histórico del Instituto, que, de no haber sido así, quedaría en la oscuridad de los legajos y quién sabe más.

\subsection{Utilidad del Instituto.}

Semanas después del plenario municipal, los periódicos de la época, y sonadamente el Diario de Las Palmas, acometen una progresiva estrategia de información social en la que la higiene y la sanidad son principales protagonistas. El trasfondo, por supuesto, es la creación del Instituto Provincial de las Canarias Orientales, pero se le rodea de cuestiones que, a poco que uno alcance, cada vez lo hacen más urgente y necesario. Con un lenguaje sencillo y práctico, los editoriales y sueltos apuntalan una mentalidad creciente en pos de la reforma sanitaria.

El lunes, 16 de agosto de 1926, el Diario situaba en la portada el texto «Organización de los servicios de Higiene y Sanidad» ${ }^{29}$, que recapitula, en lo esencial, los acuerdos municipales de julio. No obstante, introduce un detalle inesperado acerca de la cuantía económica del mantenimiento de la institución, glosando las diferentes partidas: «El sostenimiento del Instituto se calcula en 154.000 pesetas, con personal técnico -63.000-, idem auxiliar -40.000 -, Gota de leche -15.000 -, Dispensario antituberculoso -4.000-, transportes -6.000-, jornales, enfermos en el hospital de infecciosos, agua, luz, etc. $-12.000-$, Laboratorio $-12.000-\mathrm{y}$ otros gastos de escritorio. La instalación se calcula en 50 mil pesetas».

Un tanto improvisado, al menos en la redacción periodística, pero se atisba un planeamiento presupuestario e inversor, que era la duda que todavía pendía sobre el cambio de régimen. De buena gana, el periódico ofrece lo que la fibra sensible de la opinión pública quería saber. Bien es verdad que la lectura

29 Diario de Las Palmas (nº. 12.979). 
de los diarios no alcanzaba los índices de hoy en día, no obstante la minoría lectora y burguesa tenía los ojos puestos en el Instituto de Higiene, porque, entre otras cosas, los problemas de índole sanitaria e higiénica siempre habían sido un auténtico quebradero de cabeza para el tejido social, amén de que los procesos infecciosos podían afectar a cualquiera, saltando las clases sociales y sin distinguir condición ni edad. Precisamente, el miércoles, 18 de agosto, se cargan las tintas sobre el particular y, de modo especial, el redactor hace hincapié en la concienciación ciudadana al respecto de garantizar la higiene social. «La cuestión higiénica y sanitaria» ${ }^{30}$, así reza el encabezamiento, reparte por igual dosis de buena voluntad y alarma médica que culminan en «una perseverante campaña de higienización ${ }^{31}$. Las epidemias, las infecciones sobrevenidas, las malas condiciones de las viviendas, el mal tuberculoso - del que se dan cifras: 10 óbitos en julio-, son los capítulos a solucionar en la nueva apuesta del Instituto de Higiene.

De manera paulatina, la campaña informativa va ascendiendo en nivel de intensidad, en una perfecta política de acomodación del perfil ciudadano hacia la nonata institución. Es un manejo curioso de lo médico y lo científico, no obstante la bondad institucional, hacia la validación social del trasvase de diseño sanitario. Otro peldaño, en tal tesitura, es alcanzado en «Problemas municipales. II», del sábado, 28 de agosto $^{32}$, en el umbral de la vuelta de la estancia vacacional. Vuelven a registrarse los puntos conflictivos de anteriores entregas, como las «viviendas insalubres de la Isleta» ${ }^{33}$, asunto ya denunciado por el veterano cronista y doctor Domingo J. Navarro en $1896^{34}$, y que de manera insistente reaparecía como preocupación social determinante. De otro lado, la pluma del periodista hería en lo hondo de la atención de las autoridades del ramo, pues veladamente insinúa una incorrecta disposición del servicio de abastecimiento urbano: «sin agua no es posible que haya higiene pública ni privada ${ }^{35}$. Tampoco suponía novedad alguna tal evidencia, sólo era un reclamo más para preparar al lector sobre la sucesión de artículos que, definitivamente, expondrán el Instituto de Higiene al conocimiento público.

30 Diario de Las Palmas (nº. 12.981).

31 Ibid.

32 Diario de Las Palmas (nº. 12.990).

33 Ibid.

34 Navarro, D. J. (1896) Consejos de higiene pública a la Ciudad de Las Palmas. Las Palmas, Tip. «La Verdad», pág. 18.

35 Diario de Las Palmas (n. 12.990), 28.VIII.1926. 
En tal sentido, y pareciendo contestar a lo ya publicado, se indica una de las funciones del citado ${ }^{36}$ : «En el servicio de inspección de viviendas intervendrá el Instituto de Higiene de Canarias Orientales, que funciona bajo la acertada dirección del Inspector de Sanidad de este grupo D. Ortiz de Landázuri».

Es, pues, en las fechas postreras de 1926 y en los inicios de 1927, cuando se acomete, sin solución de continuidad, ni apenas miramientos, la presentación del Instituto. La cantidad y calidad de informaciones y detalles varios hacen de esta serie documental un lugar imprescindible para conocer la realidad proyectada. El jueves, 11 de noviembre de 1926, el Diario edita en primera plana «Utilidad del Instituto de Higiene y ventajas del régimen sanitario de Canarias» ${ }^{37}$, un primer eslabón de la cadena informativa. Según se dice: «El Instituto de Higiene será de efectiva utilidad y reportará grandes beneficios a la ciudad cuando se hallan organizado todos los servicios que tiene a su cargo, para lo cual necesita el personal técnico necesario».

\subsection{La organización: estructura funcional y miembros.}

Por su parte, el Cabildo Insular de Gran Canaria, hasta ahora silente en sus gestiones, al menos en lo que respecta a reflejo periodístico ${ }^{38}$, también comenzó a mover piezas en la dirección de convertir en hechos palpables los proyectos del Inspector de Sanidad. El 24 de septiembre de 1926, en sesión extraordinaria, de contenido casi único ${ }^{39}$, se aprobó el Proyecto de Reglamento del Instituto de Higiene, en información aportada por La Provincia, diario matutino, que daba complemento al Diario de la tarde. Incluso antes, ya había ordenado la provisión de una plaza de auxiliar administrativo para la plantilla de la institución sanitaria $^{40}$. En fin, parecía existir una clara voluntad política y administrativa al objeto

36 Diario de Las Palmas ( $\mathrm{n}^{\circ}$. 12.996), «Inspección sanitaria de viviendas», martes, 7 de septiembre de 1926.

37 Diario de Las Palmas ( $\mathrm{n}^{\circ}$. 13.051).

38 No así administrativo, ya que seguía el proceso desde un principio. Aunque muy parcial y decepcionante en grado sumo, pues omite cualquier alusión a Ortiz de Landázuri —ni lo nombra-, al Ayuntamiento capitalino o a las referencias de los diarios de la época, que es nuestro propósito expreso, el discurrir histórico de los comienzos del Instituto de Higiene, desde el punto de vista de la entidad cabildicia, puede encontrarse en RAMíREZ, M. (1995), Historia del Cabildo Insular de Gran Canaria (1913-1936), Las Palmas de Gran Canaria, Cabildo Insular, pp. 441-443.

39 La Provincia $\left(\mathrm{n}^{\circ} .5 .933\right)$, «Cabildo Insular».

40 La Provincia $\left(\mathrm{n}^{\circ}\right.$. 5.914), «Cabildo Insular - Comisión Insular-Sesión ordinaria para hoy. Orden de asuntos», 1.IX.1926. 
de establecer, en un tiempo razonablemente corto, el servicio higiénico, lo que contrasta con el desinterés o poco rigor de los esfuerzos de las autoridades de otras latitudes hispanas por dotarse de estos ejemplares institutos ${ }^{41}$.

Los meses de enero y febrero de 1927, a los efectos periodísticos, mostraban una decidida tendencia a la información sanitaria o, directamente, médico-asistencial en comparación con los contenidos habituales de los diarios más leídos, que se inclinaban, de manera natural, a los aspectos políticos, fueran nacionales o hicieran relación al sempiterno pleito insular. Por ejemplo, los temas tratados, de gran interés en aquel momento, indicaban que los servicios de atención a los enfermos mentales (miércoles, 12 de enero) ${ }^{42}$, la epidemia gripal (sábado, 22 y martes, 25 de enero) ${ }^{43}$ y la tuberculosis no quedaban muy lejos de la preocupación social ${ }^{44}$. Antes al contrario, son los jalones de un sumario de estudiado impacto editorial, que únicamente podía captarse en su plenitud tras la exposición divulgativa del Instituto de Higiene de Canarias Orientales.

En realidad, se hacía presentar la necesidad y luego, como remate, el bien material que habría de satisfacerla. El mal tuberculoso provocaba estragos entre la población, según la estadística comparada ofrecida por el propio Diario en marzo de 1927, en un artículo que no dejaba lugar a dudas: «La mortalidad en el año 1926». De los 1.433 óbitos producidos, la tuberculosis era la responsable de 180 muertes $^{45}$, una alta cifra que, de no poner los remedios oportunos, seguiría aumentando en el próximo ejercicio sanitario. Pues bien, con un mes de antelación, el mismo órgano informador destaca entre sus columnas un entusiasta artículo, «Obra social y humanitaria. Campaña contra la tuberculosis», demostrando que ya el Instituto de Higiene, no obstante la celeridad de su puesta en marcha y aún sin las reformas previstas en su casa ${ }^{46}$, actúa con positiva mano en la detención de la infección:

41 Huertas (2000), pág. 37.

42 Diario de Las Palmas (nº 13.100), «La Leprosería y el Manicomio», 12.I.1927.

43 Diario de Las Palmas, «Una circular interesante. La epidemia grippal», 22.I.1927 (nº. 13.109); «Precauciones contra la gripe», 25.I.1927 ( $\mathrm{n}^{\circ}$. 13.111).

44 Diario de Las Palmas (n. 13.132), «Obra social y humanitaria. Campaña contra la tuberculosis», viernes, 18 de febrero de 1927.

45 Diario de Las Palmas (nº 13.184), 18.III.1927. Desglosada la cifra, quedaría así: 148 individuos por tuberculosis pulmonar, 16 de meningítica y 16 de «otras tuberculosis».

46 Diario de Las Palmas ( $n^{\circ}$. 12.943), «Del Cabildo Insular. Sesión de la Permanente», lunes, 5 de julio de 1926: «(...) se aprueba el proyecto de reforma en la casa destinada a Instituto de Higiene, ascendiendo su presupuesto a 49.037, 18 pesetas...». Véase también RAMí- 
«Ya el Instituto de Higiene de Canarias Orientales, en poco tiempo organizado gracias a la actividad y competencia del inspector provincial de Sanidad de este grupo doctor Ortiz de Landázuri, se halla en acción, instalando diversos servicios de positiva utilidad.

Son interesantes los datos que nos suministra el Instituto de Higiene en una cartilla de propaganda sanitaria que acaba de publicar con plausible iniciativa. Abarcan los datos el periodo comprendido entre 1915-1925. En los últimos diez años la tuberculosis pulmonar ha ocasionado más de 2.000 defunciones en esta Isla, correspondiendo de ellas 1.558 a la ciudad de Las Palmas, y habiendo ocurrido 1.221 del total de esa mortalidad en personas de 20 a 39 años.

(...) Responde, pues, el Instituto a los fines de su creación y las familias necesitadas pueden utilizar los diferentes servicios establecidos, al frente de los cuales se encuentran facultativos de probada competencia» ${ }^{47}$.

En marzo de 1927, tras la campaña divulgativa y propagandística iniciada en noviembre del 26, las informaciones someten a escrutinio público el Instituto de Higiene. El detalle es preciso y el mensaje directo, puesto que había que rentabilizar al máximo la aventura administrativo-institucional. Una serie de artículos, comenzada en la primera semana del mes, pone en claro las atribuciones, la estructura funcional y el personal de atención en cada uno de los servicios. El jueves, 3 del corriente, asomaba en la portada del Diario el texto «El Instituto de Higiene de Canarias Orientales» ${ }^{48}$, primer aldabonazo que especifica el origen legal y barrunta la división competencial en su interior: «(...) En cumplimiento del Estatuto y del Reglamento provincial se creó el Instituto de Higiene de Canarias Orientales, con residencia en esta ciudad, que ya ha inaugurado sus servicios... Con arreglo al Reglamento por lo menos constará de tres [secciones]: epidemiología y desinfección; análisis (clínicos, higiénicos y químicos) y vacunaciones».

Resulta reconfortante, en la distancia histórica y con un mínimo de conocimiento de la situación sanitaria de la urbe a las espaldas, que un establecimiento de esa índole, felizmente organizado por el doctor Ortiz de Landázuri - que «en unos cuantos meses ha puesto en marcha servicios importantísimos ${ }^{49}{ }^{4}$-, abra las puertas a la atención de los enfermos. También es proverbial, todo sea dicho, el acento del redactor al adelantar la apertura de los servicios cuando restaban obras de reforma en el edificio definitivo. Justamente,

REZ, M. (2003) El Cabildo de Gran Canaria y sus presidentes. Noventa años al servicio de la Isla. Madrid, Cabildo Insular de Gran Canaria, pág,. 111.

47 Diario de Las Palmas ( ${ }^{\circ}$. 13.122), 18.II.1927.

48 Diario de Las Palmas ( $\left.\mathrm{n}^{\circ} .13 .141\right)$.

49 Ibíd. 
la nueva entrega del Diario mitiga la curiosidad por la construcción ${ }^{50}$, amén de escriturar la página histórica que ubica el Instituto de Higiene en las calles de la ciudad y no sólo en las hojas volanderas:

«Antes de instalar el Instituto de Higiene en un local sin condiciones adecuadas, lo primero que hizo el Cabildo insular fue construir un nuevo edificio como ampliación a la magnífica finca que posee en la calle de Canalejas. Desde luego ha quedado, pues, instalado el Instituto en casa apropia, cuya distribución interior se adapta a los diferentes servicios establecidos en él.

El edificio es sencillo; consta de dos plantas, principal y baja. En la parte baja han sido instalados locales de pasteurización, vacunación, de espera y de enfermeras, dispensario antituberculoso, con entrada independiente, consulta de la gota de leche, reparto y lavado de biberones, extracción de vacuna, observación, establo de terneros, garaje, servicios higiénicos, etc.

Además se proyecta una ampliación que sirva de parque de desinfección.

En el piso alto se encuentran la dirección y administración, secciones de química y bacteriológica, y antirrábica, departamentos de animales inoculados y autopsias, balanzas, etc. Hay también instalación de gas para la calefacción. Todos los departamentos de trabajo hállanse bien ventilados y llenos de luz. Puede decirse que modestamente es un modelo de instalación el Instituto de Canarias Orientales».

Es reconocible el orgullo por la factura y dimensiones del servicio. Se echa de ver la ambición con la que fue proyectado y, al parecer, también desarrollado. Sin embargo, destaca, por encima de cualesquiera otras circunstancias, que el Instituto arrostrara tal carga atencional y analítica, cuando antes los correspondientes laboratorios o estaciones habían de funcionar de forma individual, sin acompasar sus pasos en la mejora de la sanidad pública. En cierto modo, esta compensación de las funciones del Instituto se debe al personal reunido por la voluntad de Ortiz de Landázuri. Otro de los aciertos del suelto del Diario es que desglosa por secciones los miembros institucionales, tomándose cabal cuenta de la calidad científica y humana ${ }^{51}$.

50 Diario de Las Palmas ( $\mathrm{n}^{\circ}$. 13.142), «El Instituto de Higiene de Canarias Orientales. II», viernes, 4 de marzo de 1927. Véase también RAMíREZ (2003), pp. 110-111, que sitúa el centro en el ex Colegio de la Soledad.

51 Ibid., y también Diario de Las Palmas ( ${ }^{\circ}$. 13.143), «El Instituto de Higiene de Canarias Orientales: III y último», sábado, 5 de marzo de 1927. 


\section{INSTITUTO PROVINCIAL DE HIGIENE DE LAS CANARIAS ORIENTALES}

(Secciones y Jefes).

I. Sección de Bacteriología.

Alberto García Ibáñez (Médico, Jefe).

Manuel Paradas Farinós (Médico, Ayudante).

Andrea Valle (Enfermera).

II. Laboratorio Químico.

Antonio R. Vila Enríquez (Dr. en Farmacia, Jefe).

José Simón Martínez (Farmacéutico, Ayudante).

III. Dispensario antituberculoso.

Antonio González Suárez (Médico, Jefe).

María Macías del Río (Enfermera).

IV. Sección de Veterinaria.

Virgilio Santos Rodríguez (Veterinario, Jefe).

V. Higiene Prenatal.

Juan Guerra del Río (Médico, Jefe).

Carmen Alonso (Enfermera visitadora).

VI. Sección de Epidemiología e Inspección médico-escolar.

Eugenio Croissier (Médico, Jefe).

Rafaela Rodríguez (Enfermera visitadora).

VII. Consultorio de niños y Gota de leche.

Luis Manchado y Martinón (Médico, Jefe).

Antonia Guerra (Enfermera visitadora).

Merece un breve comentario la presencia del personal especializado de enfermería, así como la «gota de leche», en el dibujo del Instituto Provincial de Higiene. Ambos extremos, por extraño que parezca, obedecen a un idéntico patrón analítico. El índice de pobreza de solemnidad, el de indigencia calleje- 
ra (sobre todo, compuesta por niños ${ }^{52}$ y el de analfabetismo estaban trágicamente unidos, y esto era conocido por la clase médica insular, que, como hace al caso, procura atender no sólo a los enfermos sino facilitar un aprendizaje terapéutico entre la población de su atención.

Incluso, en los interiores del artículo del 5 de marzo, se aclara la procedencia administrativa y profesional de un amplio ramillete de médicos y el único veterinario. De su tenor, se desprende que alcanzaron las plazas, felizmente dispuestas, por oposición pública en Madrid, adonde hubieron de desplazarse con tal fin $y$, en concreto, a las salas de la Universidad Central, lugar escogido para las pruebas. Es decir, técnicos jóvenes y de sobrada preparación académica, demostrada en los concursos superados. Hizo bien el Inspector de Sanidad, don Antonio Ortiz de Landázuri, en rodearse de personas plenas de ambición y afán por el trabajo. No obstante, su figura personal mereció un atento repaso del editor, que nos descubrió el proyecto vital de un médico entregado ${ }^{53}$ :

«(...) el Dr. Ortiz es un trabajador infatigable; puede decirse que se multiplica. Se dan alientos para su obra su juventud, sus conocimientos, su espíritu altruista, sus sentimientos humanitarios. Su afán es que las clases desheredadas encuentren amparo, que los enfermos pobres sean asistidos y socorridos, que los niños se desarrollen vigorosos, que se mejore la higiene pública y privada, evitando contagios a fin de reducir la mortalidad todo lo posible».

En suma, el Instituto de Higiene de las Canarias Orientales, en lo que respecta a conocimiento público de las funciones, cometidos y personal de su adscripción, está perfectamente conectado con las preocupaciones e inquietudes de la sociedad civil del momento. Las referencias periodísticas, y aun las archivísticas, así nos lo hacen presente.

\section{CONCLUSIÓN}

A escasas fechas del Real Decreto Ley de septiembre de 1927, por el que Canarias quedaba dividida en dos provincias, ya existía una legislación que

52 «Para completar el cuadro, la turba magna de muchos [niños] casi desnudos, tirando piedras, silbando, corriendo, atropellando y maltratando a los mendigos, locos y borrachos, con infernal gritería», refiere NAVARRO (1895) sobre las calles más transitadas de Las Palmas de Gran Canaria. (Hemos citado, en este caso, por la edición del Cabildo Insular de Gran Canaria, de 1998, pág. 67).

53 Diario de Las Palmas (nº. 13.143), 5.III.1927, cit. 
permitía separar a ambos grupos de islas, fueran occidentales u orientales. El motivo de la particular quiebra administrativa era la sanidad, máxime en cumplimiento del Estatuto Provincial de 1925, al que precedió el Municipal, hijos del mismo padre, Calvo Sotelo, y así habrían de ser denominados con el tiempo, haciendo lugar a un nuevo epónimo en el cuerpo legal de la rama sanitaria española. El Instituto de Higiene de las Canarias Orientales, visto en la distancia comparativa, resultó ser uno de los que se ejecutó con relativa celeridad dentro del territorio hispano. A ello contribuyó decisivamente la firme apuesta del Ayuntamiento de Las Palmas de Gran Canaria y el Cabildo Insular de dicha isla, que no ahorraron en el esfuerzo.

Este Instituto de Higiene consolidaba, y aun fundía, anteriores servicios dispersos y mal coordinados. A partir de 1926, y con el acertado desempeño del doctor Antonio Ortiz de Landázuri, las dependencias del renovado ex Colegio de la Soledad, ahora con una función muy distinta, son el enclave sociosanitario y asistencial más importante de este sector isleño. Los periódicos, bien notificados del asunto, advierten de la presteza en el desarrollo de las ideas y el pulso equilibrado en la realización material. Este joven doctor supo allegar fuerza y vitalidad a los médicos veteranos, recuperados de los viejos laboratorios capitalinos, y ganarse el respeto y confianza de los recién llegados de las últimas oposiciones de Madrid. De su competencia se hacen todos eco y, de modo especial, el Diario de Las Palmas que no escatima en elogios. Además, Ortiz de Landázuri asume prontamente la responsabilidad, desde su cargo de la Inspección de Sanidad, para afrontar los problemas latentes de la enfermedad en Canarias. Las secciones del Instituto de Higiene informan del recto criterio con que se emprendió la tarea investigadora y terapéutica, destacando, por lo importante de la afección en el momento, el control del mal tuberculoso, que se había prodigado meses atrás, como denunciaban triste e insistentemente las estadísticas.

Esta es la parte más descriptiva del trabajo vertido hasta aquí, sólo resta apuntar las directrices regionales en las que se inscribe el Instituto de Higiene. A lo pronto, el Instituto obedece a una singular política sanitaria de corte descentralizador que posibilitó un mayor dinamismo de los profesionales de la medicina, $y$, en no menor medida, una coordinación de las actividades socioasistenciales. De otra parte, supone una carga de responsabilidad cierta sobre el Inspector de Sanidad, designado como el referente casi absoluto del sector en las Islas Orientales, a excepción del ramo de la Sanidad Exterior, todavía en manos del Ministerio. Se quiere decir que el Instituto de Higiene adquirirá, mal que le pese, un perfil personalista en la dirección del timón sanitario, como evidencian las páginas de los periódicos. No obstante, las distintas vo- 
luntades, presentes en la gestación del servicio, abundan en un comportamiento ejemplar, comandadas por el Alcalde de la ciudad, Salvador Manrique de Lara, y el Presidente del Cabildo, José de Aguilar Martín. Este último descolló, en su mandato al frente de la institución insular, como decidido defensor de la sanidad pública con una política activa y comprometida con la apertura de hospitales por la geografía isleña ${ }^{54}$.

Para finalizar, y dentro del noticiario aportado por el Instituto de Higiene, sobresale el prurito divulgador de Ortiz de Landázuri que aprovechó buenamente la ocasión de su destino profesional e hizo posible una sección de propaganda sanitaria en el recién constituido, algo no apreciable en otros servicios del mismo cariz. Y, por último, los cambios de estructura funcional o asistencial, habidos tras la novedad administrativa, fueron bien recibidos por la profesión médica, a una parte, y por los estamentos oficiales del Ayuntamiento capitalino, de otra, aunque, en un principio, les apuraba la duda sobre el Instituto y su materialización. El tiempo y la transparencia de voluntades disiparon las sombras.

\section{AGRADECIMIENTO}

Quisiera dejar expresa constancia de mi simpatía y reconocimiento por el trato recibido y el buen servicio prestado al personal auxiliar de sala del Archivo Histórico Provincial de Las Palmas y al de la hemeroteca de el Museo Canario, ambos en Las Palmas de Gran Canaria.

54 RAMíREZ (2003), pp. 102 y ss. 